\title{
Apontamentos históricos sobre crítica de mídia noticiosa
}

\author{
Wania Célia Bittencourt \\ Mestre em Jornalismo. Programa de \\ Pós-Graduação em Jornalismo da \\ Universidade Federal de Santa Catarina \\ (UFSC). Graduada em Comunicação \\ Social - Jornalismo pela Universidade \\ do Vale do Itajaí, e em Letras - Inglês \\ pela UFSC. Professora do Curso de \\ Jornalismo da Associação Educacional \\ Bom Jesus/IELUSC - SC. \\ E-mail: wania1603@yahoo.com.br
}

\section{Gislene Silva}

Professora do Programa de PósGraduação em Jornalismo da Universidade Federal de Santa Catarina (UFSC). Doutora em Ciências Sociais/Antropologia pela Pontifícia Universidade de São Paulo (PUC-SP), com pós-doutorado na Universidade de São Paulo (USP). Autora do livro $O$ sonho da casa no campo: jornalismo e imaginário de leitores urbanos.

E-mail: gislenedasilva@gmail.com
Resumo: Influenciada por modelos norte-americanos, a crítica de mídia noticiosa no Brasil já tem uma curta história. Se na prática tais iniciativas são raras e esporádicas, mais raros ainda são os estudos brasileiros sobre crítica de mídia noticiosa. Este artigo tem como objetivo organizar apontamentos históricos sobre experiências de crítica de jornalismo no país, com intenção mais ampla de, a partir desses apontamentos, fazer provocações a respeito da necessidade de se estudar a crítica de notícias como campo de pesquisa e ensino.

Palavras-chave: Jornalismo; Crítica de mídia; Media criticism; Crítica de notícia.

\section{Title: Historical notes on media criticism}

Abstract: Influenced by North-American standards, the press criticism's practice in Brazil has already had a short history. If, in practice, such initiatives are rare and sporadic, much rarer are the Brazilian studies on this topic. This essay aims to organize historical notes on media criticism in the country. The intention is, based on these notes, reflect the need to study the press review as a research and teaching field.

Keywords: Journalism; Media criticism; Press review. 


\section{Introdução}

${ }^{1}$ Todas as citações referentes ao texto de Carey são apresentadas em tradução dos autores deste estudo.
Entre as inúmeras instituições contemporâneas existentes não haveria nenhuma isenta de crítica. A observação é de Carey $(1974$, p. 235)ํ. De acordo com o autor, o próprio jornalismo se incumbiria da tarefa de apontar acertos e erros alheios. No entanto, "permanece o fato de que uma instituição se mantém curiosamente isenta de análise de crítica: a própria imprensa" (Loc. cit.). Com ironia, ele destaca a veemente resistência do jornalismo em ser criticado.

Na época em que o artigo foi escrito, Carey, ao observar a reação dos jornalistas às críticas feitas pela sociedade, concluiu que "a ideia de crítica de imprensa se tornou uma execração para os jornalistas, e a palavra em si se converteu em um farol semântico que, infalivelmente, atrai uma série de mariposas emocionais" (Ibid., p. 227). Metaforicamente, Carey identifica um receio por parte da classe profissional de que qualquer espécie de julgamento da mídia passe a ocasionar uma censura ao trabalho desenvolvido pelos jornalistas.

Os antecedentes históricos de cerceamento ao trabalho da imprensa, a sombra de experiências como órgãos censores e departamentos de regulação e mesmo práticas de conselhos de mídia ocasionam essa preocupação dos jornalistas com uma possível censura. Haveria, contudo, uma confusão entre os termos censura e crítica. Enquanto a censura caracteriza-se como "o exame prévio de conteúdo com possibilidade de restrição à sua publicação" (SILVA; PAULINO, 2010, p. 15), a crítica assemelha-se a "uma resposta ativa e contínua [...] sobre os produtos apresentados ao público" (CAREY, 1974, p. 231). A censura, portanto, antecede a produção e a publicação das notícias, enquanto a crítica busca ser uma avaliação dos produtos que já foram disponibilizados à audiência. Bertrand (2002) defende que, "uma vez entregues, os produtos precisam ser avaliados criticamente pelos consumidores" (p. 24), o que não configura qualquer espécie de cerceamento.

Embora haja uma resistência dos profissionais e dos veículos de comunicação à crítica, deve-se reconhecer a existência de iniciativas de avaliação dos produtos midiáticos denominadas crítica de mídia ou media criticism. Para Carey (1974), essas iniciativas se equiparariam a ataques ou resistências à própria mídia e, mesmo juntas, não chegariam a consolidar "uma tradição de crítica de mídia sustentada, sistemática" (p. 227). Porém, como argumenta Braga (2006), essa crítica funciona "mal, como nos parece, não nos autoriza desprezá-la" (p. 334). Ao contrário, reforça o autor, os dispositivos críticos, "ainda que apresentem algumas lacunas, estão fazendo um trabalho apreciável no ambiente geral de escassez".

Braga (2006) sustenta que esses julgamentos, ainda que incipientes, sobre as práticas e processos jornalísticos fazem parte do processo da comunicação. Além do sistema de produção, que cria conteúdos como as notícias, e do sistema de recepção, formado por leitores, espectadores e ouvintes dispostos a receber e consumir tais conteúdos, haveria o sistema de resposta social. Este, ao lado da produção e a recepção, completaria o ciclo comunicacional, correspondendo a "atividades de resposta produtiva e direcionadora da sociedade em interação com os produtos midiáticos" (Ibid., p. 22). Produtiva porque a sociedade, ao se relacionar com os produtos que assiste, lê e ouve, produziria novos significados sobre os conteúdos, muitas vezes publicando suas opiniões, divergências e colocações na própria mídia; e direcionadora porque abre caminho, de certa forma, para a circulação dos conteúdos produzidos pela mídia, gerando novos sentidos entre os próprios produtores e outros receptores, possibilitando diferentes leituras sobre um mesmo processo ou produto midiático. Inúmeras formas de interação existiriam dentro desse terceiro sistema, entre elas, a interação crítica sobre a mídia, voltada para interpretação e/ou julgamento dos produtos midiáticos.

Influenciada por modelos norte-americanos, a prática de crítica de mídia 
noticiosa no Brasil já tem uma curta história. Se na prática tais iniciativas são raras e esporádicas, mais raros ainda são os estudos brasileiros sobre crítica de mídia noticiosa. Este artigo tem como objetivo organizar apontamentos históricos sobre experiências de crítica de jornalismo no país, com intenção mais ampla de, a partir desses apontamentos, fazer provocações a respeito da necessidade de se estudar a crítica de notícias como campo de pesquisa e ensino.

\section{Media criticism: experiências pioneiras}

Um dos primeiros críticos do jornalismo foi o austríaco Karl Kraus que, por meio da sua revista Die Fackel (O Archote), tornou-se um "símbolo da imagem negativa que os intelectuais do final do século XIX e do início do século XX traçaram para o jornalismo e os jornalistas" (OLIVEIRA, 2007, p. 134). O trabalho de Kraus é considerado "um dos maiores repertórios de artigos contra o jornalismo e os jornalistas. Mestre do aforismo e da frase cortante, ele dedicou quase quatro décadas da sua vida a anotar faltas, escândalos e abusos precisos da imprensa" (Ibid., p. 135). Karl escreveu peças de dramaturgia, ensaios e 500 conferências sobre temas diversos e chegou a ser, segundo Dines (1982), "convidado para ocupar o cargo de editor do feuilleton do Neue Freie Presse", mas preferiu ficar produzindo "sozinho o pequeno folhetim, rindo de todos - de Freud, da Esquerda, da Direita, dos imortais e, sobretudo, do jornalão Neue Freie Presse que encarnava a requintada decadência vienense" (p. 152). O material produzido sobre jornalismo por Kraus, publicado em uma espécie de revista, primeiramente financiada pelo próprio pai e, posteriormente, mantida com recursos próprios, seria um dos principais trabalhos do escritor. Durante 39 anos, mais especificamente entre 1899 e 1936, ele desenvolveu "a mais ácida ironia no retrato do papel da imprensa" (OLIVEIRA, 2007, p. 134). Justamente pelo caráter irônico e decididamente parcial da produção desenvolvida por Kraus, com a intenção, literal, de combater a imprensa, a crítica desenvolvida por ele se afasta da ideia de uma análise baseada em fundamentos, aproximando-se muito mais da "manifestação cultural [...] de um satirista, debochado e iconoclasta" (DINES, 2002, p. 1).

A crítica das práticas midiáticas ensaiaria uma aproximação com o atual media criticism por meio de um trabalho desenvolvido, em 1920, pelos jornalistas norteamericanos Walter Lippmann e Charles Merz, a partir "da análise da cobertura da Revolução Russa pelo mais importante jornal americano, o The New York Times" (Loc. cit.). O artigo, produzido pela dupla de jornalistas e publicado no jornal The New Republic, "demonstra meticulosamente como o principal jornal do país prestou um desserviço ao público através de reportagens incompletas e preconceituosas, nada menos do que um desastre" (GOLDSTEIN, 2007, IX).

[Lippmann e Merz] puseram-se a colecionar tudo o que o jornal publicou a respeito da rebelião contra o governo imperial [...]. Recortaram e contaram, examinaram teores e fizeram estatísticas, compararam - do sentido das manchetes à maneira como "fontes" tornaram-se relevantes, da formulação das legendas das fotos ao destaque das matérias. (DINES, 2002, p. 1).

O fato de Lippmann e Merz terem sido movidos por procedimentos de pesquisa analítica contribuiu para que escapassem da crítica de uma mídia "idiossincrática, espasmódica e inflamada" e, assim, evitando o "panfleto indignado" (DINES, 2002). O raciocínio da dupla vinha do próprio entendimento do jornalismo como uma atividade crítica da sociedade: se a imprensa, a cada vez que publicava uma denúncia, precisava investigar e colher provas antes de publicar, a atividade crítica sobre o jornalismo deveria seguir a mesma trajetória, ou seja, investigar rigorosamente os procedimentos de produção das notícias.

Dines (2002) classifica esse trabalho como um marco fundamental na história 
do jornalismo, considerando-o como o episódio em que se "estabeleceram paradigmas definitivos e universais para obrigar a imprensa e seus profissionais a admitir a crítica". Parece, contudo, uma visão bastante otimista de Dines. Goldstein (2007, p. IX), por sua vez, identifica o trabalho de Lippmann e Merz como "parte de uma rica - e amplamente esquecida e ignorada - parte da crítica de mídia que tem surgido esporadicamente nos últimos 100 anos ou mais". Esquecida e ignorada, ressalta-se por que a crítica destinada à avaliação dos produtos jornalísticos nunca foi bem vista entre os profissionais da área.

Goldstein observa que, nos Estados Unidos, mesmo que sejam identificados julgamentos sobre a imprensa produzidos por jornalistas ou os chamados "críticos profissionais", muitas das investidas na manutenção, mesmo frágil, da crítica de mídia não foram conduzidas pelos próprios profissionais do campo, mas principalmente por meio de membros de outros setores da sociedade, como advogados, políticos e escritores. $\mathrm{O}$ autor recorda que, de uma maneira que iria se repetir por todo o século, "outsiders eram muitas vezes mais ousados e penetrantes em sua crítica do que a imprensa em si [...] usando a linguagem raramente utilizada por jornalistas na avaliação da sua perfomance" (GOLDSTEIN, 2007, p. XII, tradução nossa). Essas críticas externas à imprensa circulavam em diferentes suportes, como ensaios, palestras, colunas em jornais e até capítulos de livros, sendo que o seu principal alvo era a concentração do poder midiático nas mãos de poucos grupos. Apesar de louváveis, principalmente por apresentarem uma abordagem inversa à do pensamento dominante sobre o jornalismo, a maioria dessas críticas tinha um tom "ultrajante e irreverente" que se afastava do modelo mais analítico produzido inicialmente pelos jornalistas Lippmann e Merz.

As preocupações até então esparsas sobre a qualidade do jornalismo e sobre as possíveis interferências na independência e na liberdade dos jornais serão endossadas, a partir da década de 1940, por uma pesquisa desenvolvida pela Universidade de Chicago, nos Estados Unidos. A pedido da empresa Time Inc., que custeou o projeto, com o apoio da Enciclopédia Britânica, o reitor da universidade, Robert Hutchins, montou uma equipe de estudiosos, a Comission

${ }^{2}$ Sob o nome de press, a Comissão Hutchins considerava não apenas a imprensa, como é conhecida no Brasil, formada por jornais e revistas nos formatos impressos, televisivos e radiofônicos, mas englobava produtos cinematográficos, livros, propagandas, entre outros produtos midiáticos. on the Freedom of Press (conhecida como Comissão Hutchins ${ }^{2}$ ), com a intenção de investigar "o estado presente e prospectos futuros da liberdade de imprensa" (HUTCHINS, 1947, p. V, tradução nossa). Ao todo, foram colhidos depoimentos de 58 pessoas diretamente ligadas à imprensa e feitas 225 entrevistas com membros da indústria, do governo e de agências privadas, todos, de alguma forma, preocupados com a qualidade e a produção da mídia. Foram ainda organizados 17 encontros de discussão sobre o assunto. $O$ resultado do trabalho, publicado em 1947 e nomeado A Free and Responsible Press - A General Report on Mass Communication, Newspaper, Radio, Motion Pictures, Magazines, and Books, traça uma relação entre liberdade de imprensa, responsabilidade social e crítica de mídia. Conclusivamente, o relatório mostra que "a comissão está ciente de que as agências de comunicação de massa não são as únicas a influenciar a formação da cultura e opinião pública norte-americana. Mas, juntas, são provavelmente a influência mais poderosa hoje" e ressalva que este "relativo poder das agências faz com que tenham grandes obrigações" (HUTCHINS, 1947, p. VII, tradução nossa). Na verdade, "o relatório da Comissão Hutchins propunha uma nova agenda a partir de um conjunto de orientações que apelavam à responsabilidade como contrapartida à liberdade de imprensa" (PAULINO, 2010, p. 39), algo que deveria funcionar com a ajuda dos jornalistas, das empresas e da própria sociedade.

Uma das principais condutas apresentadas pela comissão para alcançar esse compromisso de responsabilidade social na oferta de conteúdos ao público seria a crítica mútua, ou seja, a crítica da imprensa produzida pelos próprios profissionais da comunicação e pela sociedade que consome os seus produtos. O relatório já identificava a confusão no entendimento do termo liberdade, tal como defendida pelos proprietários dos veículos de comunicação, e a dificuldade por parte dos 
membros da mídia em aceitar as críticas. Sobreavisa, por exemplo, que "uma das principais maneiras mais efetivas de se melhorar a mídia é bloqueada por ela mesma. Por uma espécie de lei não escrita, a imprensa ignora os erros e as deturpações, as mentiras e os escândalos das quais os seus membros são culpados" (HUTCHINS, 1947, p. 65-66, tradução nossa). E pede que a imprensa "abandone a prática de recusar comentário mútuo e adote um decidido policiamento por meio da crítica da imprensa e pela imprensa".

Padrões profissionais não são possíveis de ser alcançados enquanto as falhas e os erros, as fraudes e os crimes, cometidos pela imprensa, forem silenciados pelos outros membros da profissão. [...] A formalização da imprensa como uma profissão, com o poder de privar um membro que errou da sua atuação, é improvável e talvez indesejável. Temos evidenciado repetidamente o desejo de que o poder do governo não deve ser invocado para punir as aberrações da imprensa. Se a imprensa é para ser responsabilizada e se quer se manter livre, seus membros devem disciplinar uns aos outros e o único meio que eles têm disponível é a crítica pública. (Ibid., p. 94, tradução nossa).

De acordo com Goldstein (2007), o apelo para o desenvolvimento de crítica de mídia feito pela Comissão Hutchins caiu em "ouvidos surdos". Imediatamente após a publicação e divulgação do relatório, houve uma reação contrária às colocações feitas pelos pesquisadores da Universidade de Chicago, reiterando o discurso que traça uma relação direta e equivocada entre crítica e censura. Seriam abafadas, mais uma vez, as possibilidades de instituição de um fórum amplo para a discussão dos processos e práticas jornalísticas. Paulino (2010, p. 39) explica que "o texto provocou polêmica ao propor a criação de um órgão independente para avaliar a atuação da mídia e recebeu críticas de grande parte das instituições de comunicação, receosas de regulamentações que se materializassem em interferências restritivas à liberdade de imprensa".

Ainda que as reações ao relatório não tenham sido tão positivas quanto esperavam os pesquisadores, não afetando diretamente a relação entre jornalismo e crítica, resoluções positivas foram retiradas da experiência, especialmente no que se refere ao caráter ético da profissão. A partir do relatório, passou-se a discutir mais amplamente a Teoria da Responsabilidade Social da Imprensa, "uma possível base para se fundamentar um sistema de jornalismo ético, à medida que estabelece como princípio central a ideia de que os comunicadores estão obrigados a serem responsáveis com seu público, prestando conta de suas atividades" (Ibid., p. 38). O relatório, ao definir a "necessidade de os jornalistas conciliarem liberdade e responsabilidade, se tornaria célebre e incontornavelmente citado pelos manuais de ética e deontologia" (OLIVEIRA, 2007, p. 164).

Anos depois da divulgação do relatório da Comissão Hutchins, diferentes mecanismos voltados para a crítica da mídia foram desenvolvidos nos Estados Unidos e importados por outros países. Entre os mais conhecidos está o ombudsman. $\mathrm{O}$ ofício foi espelhado em um cargo público da Suécia. Conforme explica Jacoby (2002, p. 223), "os sábios suecos, sabendo que o Estado e a sua

3 Durante muitos anos, os Estados Unidos eram identificados como o país em que foi criado o primeiro ombudsman da imprensa. No entanto, na década de 1990, após trocas de informações, passou-se a reconhecer que a primeira experiência, nesse sentido, foi criada no Japão, no periódico The Yomiuri Shimbun, em 1922. Informações mais detalhadas podem ser consultadas no artigo Os MAS no Japão - Uma batalha para abrir o mundo da mídia, de Takeshi Maezawa, publicado no livro O Arsenal da Democracia, de Claude-Jean Bertrand (2002). burocracia não são respeitadores da liberdade, estabeleceram este conceito de 'cão de guarda' a serviço dos cidadãos". Transportando o conceito para o campo do Jornalismo, o ombudsman teria como a principal função ser uma espécie de porta-voz do público dentro da redação. O primeiro cargo de ombudsman da imprensa ocidental foi implantado no Courier-Journal, de Lousville, no Kentucky, em 1967, ocupado pelo jornalista John Herchenroeder ${ }^{3}$. Apesar de, na concepção original, o ombudsman devesse interferir nas decisões e publicações do jornal, estando "a serviço do público", relatos dessa primeira experiência indicam que Herchenroeder atuava como uma espécie de secretário da redação, sendo "encarregado das queixas dos leitores" e, a partir delas, produzia um relatório distribuído internamente aos profissionais, não fazendo "nenhum comentário 
público" (GLASSER, 2002, p. 215). A imagem de um ombudsman que analisa a produção jornalística do veículo de comunicação em que atua e publica suas observações no próprio jornal, como conhecido hoje, surge somente em 1970, no jornal norte-americano Washington Post, que instituiu a coluna chamada The News Business, com comentários internos e externos sobre a redação e seus produtos.

No Brasil, "o exemplo mais consistente da presença desse profissional [o ombudsman] nas empresas jornalísticas brasileiras é o do jornal Folha de S. Paulo" (LOURES, 2008, p. 169). Inspirado em experiências norte-americanas e europeias, o diário brasileiro instituiu o cargo oficialmente em 1989, que permanece ativo até os dias de hoje. Outros veículos também adotaram a ideia: o jornal $O$ Povo, de Fortaleza (CE), em 1994; a rádio AM Povo/CBN, de Fortaleza (CE), em 1998; a Rádio Bandeirantes e a TV Cultura, em 2004.

Apesar de o ombudsman parecer, de certa forma, uma resposta positiva, ainda que tardia, ao relatório da Comissão Hutchins, muitos são os questionamentos sobre a qualidade e a validade da atuação destes profissionais. Não há clareza sobre quais as funções, os limites e as responsabilidades desse cargo, que se modifica dependendo da redação. A principal contestação gira em torno da aparente dupla ocupação do ombudsman: ao mesmo tempo em que deve "servir ao público", ele remete-se à chefia da redação e tem o seu salário pago pela empresa que, supostamente, deveria questionar. Em decorrência disso, os textos produzidos por esse profissional tendem a preencher "uma função de relações públicas para os jornais e não asseguram um aporte regular de comentário crítico sobre a imprensa local" (GLASSER, 2002, p. 219). Serviriam mais para justificar os erros perante o público do que, necessariamente, cobrar uma postura diferente por parte de jornalistas e da própria empresa jornalística. Por não funcionarem como um fórum de debate entre produtores e consumidores, "tendem a restringir o debate e a limitar a crítica circunscrevendo a discussão aos jornalistas e a outros peritos internos ao mundo da mídia" (Ibid., p. 220). Para Carey (1974, p. 238, tradução nossa), por serem produzidos internamente, esses textos apenas reproduzem o olhar de quem está acostumado com aquela rotina, não sobrando espaço para o desenvolvimento de uma "crítica sustentada de intelectuais, professores, escritores e cidadãos, que estão do lado de fora do aparato dos jornais".

Outra experiência que surge nos Estados Unidos, que terá o crescimento registrado no fim da década de 1960 e início da década de 1970, são as revistas críticas, conhecidas como journalism reviews (JR), que abrangiam as principais cidades norte-americanas e observavam os principais jornais do país. As JR podem ser definidas como "um periódico (ou mais raramente um programa de rádio ou televisão) consagrado à mídia e antes de tudo à crítica desta" (BERTRAND, 2002 , p. 241). A primeira JR nasceu, efetivamente, em 1940, com o nome de In Fact, tendo durado até o ano de 1950. Somente em 1968 haveria uma explosão editorial dessas publicações.

O movimento norte-americano nasceu em outubro de 1968, quando um grupo de jornalistas de Chicago trouxe a público seu furor contra a imprensa local: eles criaram um modelo para as cerca de $25 \mathrm{JR}$ que iam ser lançadas no decurso dos cinco anos seguintes. Foi um período de intensa observação e monitoramento da imprensa norte-americana, quando também passaram a surgir conselhos de imprensa, comissões de deontologia e a intensificar 0 trabalho de pesquisadores universitários. (BERTRAND, 2002, p. 242).

As JR eram produzidas por jornalistas, em grandes e pequenas cidades, e por profissionais do meio acadêmico, dentro das universidades. Por problemas com as formas de financiamento do produto e a pouca aderência do público-alvo, 
composto por membros de sindicatos, professores e os próprios jornalistas, a maioria não durou mais do que dois anos. Muitas delas não tinham uma boa imagem perante os profissionais das redações, sendo acusadas, muitas vezes, de "serem medíocres ninharias, veículos de vaidade pessoal, folhas de recriminação, atentados dissimulados contra a livre iniciativa ou mesmo incentivos à intervenção governamental" (Ibid., p. 254). Com a dificuldade de se manter financeiramente, os artigos publicados nas JR tinham caráter colaborativo. No entanto, muitas vezes, duvidava-se da sua qualidade. De acordo com Bertrand (2002, p. 255), os artigos costumavam ser "mal documentados, mal construídos, mal escritos" e as JR locais não distinguiam "uma explosão retórica de uma investigação séria, que confundem mexericos de sala de redação com revelações úteis, que planejam vinganças pessoais contra queixas legítimas". Bertrand (2002) explica que essas publicações exigiam que a mídia dedicasse tempo para a verificação de informações, que apresentasse sempre o outro lado da história e que fizessem a releitura das provas de possíveis denúncias. Porém, internamente, poucos artigos publicados nas JR se dedicavam a seguir essas regras tão cobradas do jornalismo comercial.

\section{Crítica de mídia noticiosa no Brasil}

Iniciativas de crítica de mídia noticiosa no Brasil foram geralmente influenciadas por experiências desenvolvidas nos Estados Unidos, práticas tais como a criação de cargos como o ombudsman e a instituição de observatórios de imprensa. Para Alberto Dines, o pioneiro da atividade crítica sobre o jornalismo no Brasil seria Lima Barreto, que "ousou ridicularizar não apenas as panelinhas literárias que se abrigavam nas redações dos grandes jornais, como também o jogo do poder" (DINES, 1982, p. 150). Tal crítica seria capaz de mostrar que o jornalismo, como instituição, "jamais foi uma ferramenta a serviço da sociedade", estando sempre "adaptada aos escopos de uma competição política que visava apenas à alternância de grupos e não de ideias no comando do processo decisório" (Loc. cit.). Posteriormente, jornalistas como Godin da Fonseca, Otávio Malta e Paulo Francis, entre as décadas de 1940 e 1960, teriam se dedicado a observar e comentar o trabalho da imprensa. O primeiro exerceu a função de crítico em diferentes jornais, entre eles $O$ Mundo, enquanto Malta e Francis atuaram no Última Hora, de Samuel Wainer. Nenhum deles, no entanto, teria criticado a imprensa como instituição. Eles, segundo Dines, teriam desmascarado "jornais, jornalistas ou desempenhos jornalísticos que em sua ótica estavam errados. Mas não feriam a estrutura nem o processo como um todo porque, cada um deles em sua respectiva trincheira era fruto da mesma árvore" (Loc. cit.).

Na avaliação de José Marques de Melo (1986), seria o próprio jornalista Alberto Dines o pioneiro no media criticism brasileiro, por meio da coluna Jornal dos Jornais, publicada aos domingos na Folha de S. Paulo, entre os anos de 1975 e 1977. Dines acabara de retornar dos Estados Unidos após um período como professor-visitante na Columbia University, em Nova York, no ano acadêmico de 1974-1975, quando foi chamado pelo diretor do jornal, Otávio Frias, para se tornar colaborador da empresa, atuando como "chefe da sucursal do Rio de Janeiro e também para escrever um artigo político diário. Aceitou o desafio [...] e disse que queria fazer uma coluna de crítica de imprensa [...] No domingo seguinte à conversa, foi publicada pela primeira vez a coluna" (LOURES, 2008, p. 162-163). O conteúdo era composto de "observações e percepções do nosso cotidiano jornalístico cuja riqueza circunstancial as torna fragmentos indispensáveis à compreensão dos fenômenos que ocorreram naqueles tempos de autoritarismo" (MELO, M. 1986, p. 13). Dines comentava não apenas a atuação do próprio jornal em que trabalhava, mas de toda a mídia, levando em conta o contexto político e social da época. Em função das pressões da ditadura militar, a coluna foi encerrada por decisão dos proprietários dos jornais em 1977. 
${ }^{4}$ De acordo com Jawnicker (2008), "a publicação circulou com três nomes: nas seis primeiras edições saiu como Cadernos de Jornalismo. Em seguida, como Cadernos de Jornalismo e Editoração e, finalmente, como Cadernos de Jornalismo e Comunicação." Na citação em questão, mantivemos a escolha da autora.
Ainda segundo Marques de Melo, embora o Jornal dos Jornais seja um marco dos primórdios do media criticism brasileiro, o próprio Dines, anteriormente, já havia se dedicado a criticar a imprensa brasileira. "Em visita ao World Press Institute (vinculado à Universidade de Columbia - EUA), Dines encantou-se com o boletim do The New York Times: 'Vencedores e Pecadores', que fazia a crítica interna ao jornal". A partir da experiência, em 1965, ele e o jornalista Fernando Gabeira, que trabalhavam no Jornal do Brasil, "resolveram lançar uma publicação que fosse um fórum de críticas à mídia, em 1965" (LOURES, 2008, p. 161), uma espécie de revista que circulava internamente ao jornal, conhecida como Cadernos de Jornalismo e Editoração ${ }^{4}$. De acordo com Jawsnicker (2008, p. 153), ao todo foram publicadas 49 edições, com periodicidade irregular.

Paralelamente, outras atividades começaram a surgir no país: em 1972 nasceram os Cadernos de Comunicação Proal, da Editora e Comunicação Proal, de Manoel Carlos da Conceição Chaparro, Francisco Gaudêncio Torquato do Rêgo e Carlos Eduardo Lins da Silva, uma publicação sobre a mídia que circulava no meio acadêmico; em 1977, o Jornal da Cesta, coluna publicada no jornal alternativo Pasquim; e o livro $O$ papel do jornal, também de Dines (LOURES, 2008).

O conjunto destas experiências, ainda que isoladas e pouco duradouras, ajudaram a construir o que é conhecido como media criticism no Brasil. Dines, em artigo publicado nos anais da Intercom, em 1982, enfatiza o caráter rebelde da atividade. Segundo o jornalista, o crítico de mídia precisa se reconhecer como "um maldito, um renunciante, abrindo mão de um lugar ao sol no establishment" (DINES, 1982, p. 151). E defende que "o media criticism, como de resto toda a função crítica levada às últimas consequências, é necessariamente subversivo" (Ibid., p. 152). Para que o media criticism exista "é indispensável que seja vocalizado sem constrangimentos, à margem do status quo e, não, esmagado dentro dele." (Ibid., p. 151). E sugere que a crítica abasteça a imprensa alternativa, nas quais as pressões internas não interfeririam na avaliação do jornalismo.

$\mathrm{Na}$ opinião de Dines, aqueles que consideram séria a atividade de crítico deveriam "acrescentar uma contribuição pessoal no exame de obras ou atuações" ou "procurar fazer dissecações sobre os usos, costumes e das ideias em voga" (Ibid., p. 148). Ele lança algumas noções sobre um modo de operação do crítico de mídia. Contudo, sua preocupação, naquele momento histórico, tomava a crítica de mídia como uma resistência aos grandes veículos de comunicação, que (já) monopolizavam o cenário da mídia no Brasil, país em busca de redemocratização. Por isso, mais do que apresentar um modo para se fazer a crítica, o autor defendia sua importância, explicando a sua função no meio midiático e os possíveis resultados da sua resistência. Com isso, aponta a direção em que a crítica de mídia segue no Brasil: um espaço de enunciação externo aos jornais, oferecendo uma resistência ao jornalismo enquanto instituição, ou seja, com a sua relação com a política, na forma de observação e monitoramento das práticas midiáticas, especialmente com as funções de exigir uma melhor atuação da imprensa e, ao mesmo tempo, ensinar o público a ler a mídia.

Quase 15 anos após da publicação do artigo, o jornalista encabeça uma das iniciativas mais conhecidas e persistentes de crítica no Brasil, o site Observatório da Imprensa (OI). Lançado em 1996, com o lema "Você nunca mais vai ler jornal do mesmo jeito", o projeto surgiu dentro do Laboratório de Estudos Avançados em Jornalismo (Labjor) da Universidade Estadual de Campinas (Unicamp) e atualmente é mantido pelo Instituto para o Desenvolvimento do Jornalismo (Projor), organização social sem fins lucrativos voltada para atividades de formação, treinamento, reciclagem e consultoria. A inspiração veio do Observatório de Imprensa de Lisboa, de Portugal e, em seu próprio site, o Ol de Dines se define como um "fórum permanente onde os usuários da mídia - leitores, ouvintes, telespectadores e internautas -, organizados em associações desvinculadas do 
${ }^{5}$ Informações disponíveis no site Observatório da Imprensa. estabelecimento jornalístico, poderão manifestar-se e participar ativamente num processo no qual, até há pouco, desempenhavam o papel de agentes passivos." 5 . Em 1998, ganhou uma versão televisiva; no rádio, estreou em 2005.

Pesquisas na área de Comunicação recorrentemente levantam a importância do OI no cenário de crítica de mídia brasileira. Loures (2008, p. 165-166) descreve o site como "a experiência de crítica de mídia que alcançou até o momento maior visibilidade na sociedade brasileira", podendo ser reconhecido como o "pioneiro na prática sistemática do media criticism". Se Dines foi influenciado por modelos norte-americanos e europeus de media criticism, as iniciativas encabeçadas por ele no Brasil, especialmente o OI, serviram de motivação para a criação de outros observatórios, criados como entidades civis ou vinculados a universidades. $\mathrm{O}$ OI "mobilizou os espíritos críticos e reflexivos em relação ao acompanhamento da atividade jornalística, inspirou também o ambiente acadêmico a fazer parte deste projeto" (GUERRA, 2007, p. 4). Rothberg (2010) identifica os principais interesses dos observatórios:

a) oferecer ao público em geral um conjunto de balizas para avaliar a adequação das mídias jornalísticas em relação ao que delas deve se esperar como compromisso com a cidadania, aqui entendida como direito civil de liberdade de informação; b) compor um meio coadjuvante na formação universitária na área de comunicação e jornalismo; c) divulgar um painel para que os próprios jornalistas sejam incentivados a refletir sobre seus acertos e eventuais falhas. (ROTHBERG, 2010, p. 53).

Em 1998, foi cogitada a possibilidade de criação de uma rede de observatórios, com a intenção de possibilitar um intercâmbio de experiências sobre a rotina e prática da produção de críticas de mídia. Por inúmeras dificuldades, o projeto só veio efetivamente a se concretizar em 2005, quando foi criada a Rede Nacional de Observatório de Imprensa (Renoi), uma associação colaborativa dedicada ao fortalecimento da crítica produzida dentro e fora do ambiente acadêmico. De acordo com Christofoletti e Damas (2006), a "Renoi tem sido ativa, do ponto de vista produtivo, e também consolidado relações. Seus membros têm frequentemente trocado informações [...] Além disso, grupos de debate são articulados em eventos acadêmicos a fim de fortalecer os contatos e as iniciativas".

Entre 2006 e 2007, levantamento produzido por membros da Renoi registravam a existência de aproximadamente 20 observatórios acadêmicos no Brasil, envolvendo 31 professores-pesquisadores e 220 estudantes em 10 estados. Dados do próprio site da instituição, mais especificamente da seção "Elos da rede", datados de 2013, indicam que o grupo conta com 13 observatórios acadêmicos ou pertencentes à sociedade civil ${ }^{6}$. Em levantamento feito por Guerra (2007, p. 16), apesar das inúmeras divergências entre os grupos, o pesquisador concluiu que "embora os grupos tenham as suas peculiaridades, que devem ser reconhecidas e respeitadas, há sinais de convergência que podem ser explorados sem que nenhum deles perca a sua própria identidade".

Esses observatórios integrantes do Renoi, bem como outros mecanismos de crítica de mídia já supracitados, como colunas de ombudsman, journalism reviews, foram categorizados por Bertrand (2002) como media accountability system ou meios de responsabilização da mídia (MAS). Em definição proposta pelo autor, os MAS seriam "qualquer meio de incitar a mídia a cumprir adequadamente o seu papel: pode ser uma pessoa ou um grupo, um texto ou um programa, um processo longo ou curto" (BERTRAND, 2002, p. 10). Ao todo, haveria mais de sessenta formatos de MAS, exercendo um "misto de controle de qualidade, serviço ao consumidor, educação contínua e muito mais - não apenas, decerto, auto-regulamentação" (Ibid., p. 35). Em outras palavras, Bertrand (2002, p. 55) considera que "os MAS são armas poderosas, embora brandas, [...] para garantir 
${ }^{7}$ Dois exemplos seriam os livros Observatórios de Mídia e Vitrine de Vidraça que, ainda que teorizem sobre o assunto, são compostos por autores que também integram alguma rede de observatórios. que um melhor serviço ao público seja fornecido pelos meios de comunicação e que os jornalistas recuperem a confiança e o favor do público". Ao depositar suas esperanças na melhoria da mídia por meio da crítica, o autor resume o caráter engajado da literatura existente sobre o assunto. $O$ trabalho de Bertrand, assim como de outros autores que se dedicaram a discutir o tema da crítica, mais do que pensar e discutir teorias ou metodologias sobre crítica de mídia, ou ainda compreender os processos críticos já existentes, acaba por defender a importância da crítica.

O caráter engajado dessa bibliografia torna-se notório quando se percebe que esses autores não apenas se dedicaram a escrever sobre o assunto, mas fazem ou já fizeram parte de algum dispositivo crítico, especialmente dos sites de observatórios de imprensa. De alguma forma, a produção bibliográfica sobre o tema é um meio de validar a própria atividade destes críticos. Seria possível dizer, por exemplo, que Dines (1984; 2012) escreve sobre media criticism para legitimar a crítica, mas também para validar a sua posição de crítico. Igual é a postura de autores contemporâneos que escrevem sobre crítica e, ao mesmo tempo, participam de ações como as da Rede Nacional de Observatórios de Imprensa (Renoi).

Da mesma forma que esses autores reiteram a necessidade de se consolidar a crítica de mídia ao aderirem a essa prática por meio de diferentes dispositivos, eles impõem um tom de militância à crítica em si mesma. Militância que endereça as críticas especialmente aos grandes conglomerados de comunicação, àqueles que a ignoram ou recusam a existência da crítica. Christofoletti (2003), ao identificar os impasses para uma efetiva crítica de mídia no Brasil, vê a concentração do poder midiático nas mãos de poucos grupos como um dos principais entraves para o desenvolvimento dessa prática. Dines (1982, p. 151), por sua vez, julga necessário que a crítica destine-se a "enquadrar a estrutura que cria, estimula e orienta" o jornalismo tal como é praticado nos dias de hoje e que, automaticamente, marginaliza os media critics. As críticas são também no entendimento de Christofoletti e Motta (2008, p. 21) "uma resistência ao excessivo centralismo da mídia e impermeabilidade da indústria cultural e informativa".

Em decorrência de seu caráter reativo e de contraposição, as críticas se distanciariam da ideia de uma análise baseada em critérios. Ao analisar mais detidamente o caso do Observatório da Imprensa, Braga (2006, p. 115) constata que a crítica publicada no site se "afasta decididamente da possibilidade de 'distanciamento crítico' ou de análise estritamente 'profissional', digamos técnica, baseadas nas 'boas regras' do bem apurar e do bem redigir". Ou seja, eles não observam detalhadamente ou descrevem como o jornalismo atua, mas impõem um padrão de exigências sobre como ele deveria atuar. Braga (2006, p. 131) conclui que o OI tenta "esclarecer (as posições defendidas) e obter a adesão para esse [o seu] ponto de vista". Em decorrência dessa característica de militância, esse observatório funcionaria, na análise de Albuquerque, Ladeira e Silva (2001), mais como um agente, catalisando opiniões que se assemelhem à posição que pretende defender do que uma arena aberta ao debate sobre a mídia.

[o lugar da edição] permite ao Observatório da Imprensa não apenas destacar o seu próprio discurso, como também hierarquizar os demais, atribuindoIhes maior ou menor pertinência. Em decorrência disso, o Observatório, não obstante ser um espaço polifônico, se apresenta como um espaço muito menos plural do que nos parecia ser em princípio. (ALBUQUERQUE; LADEIRA; SILVA, 2001, p. 185).

\section{Considerações finais}

Hoje, cada vez que uma notícia, uma cobertura jornalística ou um tema recebe comentários de críticos, o debate gira em torno de "esmiuçar incansavelmente o 
verdadeiro sentido de 'interesse público', 'jornalismo de qualidade', 'liberdade', 'responsabilidade"' fazendo com que a discussão "se dissolva em um debate filosófico sobre valores universais e natureza humana" (BERTRAND, 2002, p. 53). Também Carey $(1974$, p. 243) preocupa-se com a possibilidade de que estes dispositivos de crítica de mídia possam se tornar meros processos burocráticos, discutindo sobre os hábitos abstratos da profissão, o direito à informação, os recursos de proteção aos repórteres, as normas e os cânones da profissão, não ajudando no entendimento das práticas jornalísticas como elas realmente funcionam e não necessariamente sobre como elas deveriam funcionar.

Para Braga (2006, p. 60), não soubemos ainda desenvolver, no campo midiático, dispositivos críticos capazes "de tensionar produtivamente os trabalhos de criação e produção, nem eficazmente estimular, cobrar, avaliar e selecionar bons produtos, nem ainda oferecer bases eficazes para interpretação direta no ambiente do usuário". Como sugestão, o autor propõe analisar mais especificamente os produtos, assim como já ocorre tradicionalmente na crítica cultural. De acordo com Braga (2006, p. 61), "quanto mais desenvolvidos sejam os dispositivos críticos, mais provavelmente eles se voltam para a análise de produtos específicos (e menos para análises do meio em sua generalidade)". As principais análises críticas sobre o jornalismo, hoje, acabariam por investigá-lo mais como um meio de comunicação, como a televisão, o jornal e o rádio, em vez de se dedicar a observar diferentes produtos que compõem esses meios, indicando possíveis similaridades e diferenças.

Esses apontamentos históricos sinalizam para o complexo debate sobre quem deve ou pode fazer a crítica de mídia noticiosa. Embora diga que a crítica à imprensa não deva ser exclusiva de jornais e jornalistas profissionais (CAREY, 1974, p. 239), Carey dá peso para "o incentivo de uma tradição ativa e crítica e um corpo importante de críticos profissionais" (Ibidem, p. 240) ${ }^{8}$. No esforço de pensar além da defesa da necessidade da crítica aos meios de comunicação, Ciro Marcondes Filho percebe um vazio de sugestões de como a crítica deve proceder e pergunta "quem pode fazer a crítica?", "que critérios (valores) deve utilizar?", "com que intencionalidade a crítica resgata seu sentido na sociedade atual?" (MARCONDES FILHO, 2002, p. 22). Temos aqui apontadas pelo autor questões centrais nessa discussão: (1) da autoridade, direito e liberdade para criticar; (2) dos parâmetros de como se operar a valoração da qualidade do objeto que está sob apreciação; e (3) da finalidade última de qualquer crítica, que deseja, extrapolando o esforço de compreensão, promover alguma ação de transformação do mundo ao redor. Silva e Soares agregam uma quarta questão: "a quem cabe sistematizar, aprimorar ou desenvolver os critérios de apreciação dos produtos midiáticos com base em seus antecedentes e desdobramentos?", e sugerem que a crítica de mídia no país "está reclamando ser tratada como campo particular de pesquisa e ensino" (SILVA; SOARES, 2013, p. 836). Dentro desse campo, a crítica de notícia demandará investimento acadêmico em suas particularidades.

\section{Referências Bibliográficas}

ALBUQUERQUE, A.; LADEIRA, J. D. M.; SILVA, M. A. R. Media criticism à brasileira: o Observatório da Imprensa. Revista Brasileira de Ciências da Comunicação, Rio de Janeiro, v. XXV, n. 2, jul/dez de 2002. Disponível em: <http://www.portcom.intercom.org.br/ revistas/index.php/revistaintercom/article/viewFile/427/396>. Acesso em 09 nov. 2015.

BERTRAND, Claude-Jean. $O$ arsenal da democracia: sistemas de responsabilização da mídia. Bauru: Edusc, 2002.

BITTENCOURT, W. C. Critérios de crítica de mídia noticiosa: uma investigação a partir da polêmica do livro didático. 2014, 162 f. Dissertação (Mestrado em Jornalismo) - Universidade Federal de Santa Catarina, Santa Catarina, 2014. 
BRAGA, J. L. A sociedade enfrenta sua mídia: dispositivos sociais de crítica midiática. São Paulo: Paulus, 2006.

CAREY, J. Journalism and criticism: The case of an undeveloped profession. The Review of Politics, v. 36, n. 2, p. 227-249, 1974.

CHRISTOFOLETTI, R. Dez impasses para uma efetiva crítica da mídia no Brasil. CONGRESSO BRASILEIRO DE CIÊNCIAS DA COMUNICAÇÃO, 26. Belo Horizonte, setembro de 2003. Anais... São Paulo: Intercom, 2003. [cd-rom]

CHRISTOFOLETTI, R.; DAMAS, S. H. Media watchers: a profile of press criticism in Latin America. Brazilian Journalism Research, Brasília, v. 2, n. 2, p. 11-28, jun. 2006.

CHRISTOFOlETTI, R.; MOTTA, L. G. Observatórios de mídia. São Paulo: Paulus, 2008. p. 19-38.

DINES, A. 85 anos de crítica de mídia. 2002. Disponível em: <http://www. observatoriodaimprensa.com.br/artigos/mt201120021.htm>. Acesso em: 20 mar. 2013.DINES, A. Mediacriticism: um espaço mal-dito. In: SILVA, C. E. L. da. Comunicação, hegemonia e contra-informação. São Paulo: Editora Cortez, 1982. p. 147-154.

GLASSER, T. O ombudsman de imprensa Unidos nos Estados. In: BERTRAND, C.-J. $O$ arsenal da democracia. Bauru: Edusc, 2002. p. 213-221.

GOLDSTEIN, T. Killing the messenger: 100 years of media criticism. Nova York: Columbia University Press, 2007.

GUERRA, J. Rede Nacional de observatórios da imprensa: um panorama inicial. 2007. Disponível em: <http://www.observatoriodaimprensa.com. $\mathrm{br} / \mathrm{news} / \mathrm{view} /$ rede-nacional-de-observatorios-de-imprensa-um-panoramainicial>. Acesso em: 15 jul. 2013.

JACOBY, Al. Um ombudsman de jornal: memórias pessoais dos primeiros tempos. In: BERTRAND, Claude-jean. $O$ arsenal da democracia. Bauru: Edusc, 2002. p. 223229.

JAWSNICKER, C. Cadernos de jornalismo e comunicação: iniciativa precursora de media criticism no Brasil. Revista Alceu, Rio de Janeiro, v. 8, n. 16, p. 150-158, 2008.

HUTCHINS, R. M. et al. A free and responsible press a general report on mass communication: newspapers, radio, motion pictures, magazines, and books by the commission on freedom of the press. Chicago: University of Chicago Press, 1947.

LOURES, A. C. C. Pequena história da crítica de mídia no Brasil. Um observatório, mais observatórios. In: CHRISTOFOLETTI, R.; MOTTA, L. G. Observatórios de mídia. São Paulo: Paulus, 2008. p. 19-38.

MARCONDES FILHO, C. Media criticism ou o dilema do espetáculo de massas. In: AIDAR PRADO, J. L. (Org.). Crítica das práticas midiáticas. São Paulo: Hacker, 2002, p. 14-26.

MELO, J. M. Apresentação. In: DINES, A. O papel do jornal: uma releitura. São Paulo: Summus Editorial, 1986.

OBSERVATÓRIO DA IMPRENSA. Disponível em: <www.observatoriodaimprensa. com.br>. Acesso em: 10 nov. 2015. 
OLIVEIRA, Maria Madalena da Costa. Metajornalismo... ou quando o jornalismo é sujeito do próprio discurso. 2007. 347 f. Tese (Doutoramento) - Universidade do Minho, Braga, 2007.

PAULINO, F. O. Responsabilidade social da mídia: análise conceitual e perspectivas de aplicação no Brasil, em Portugal e na Espanha. In: CHRISTOFOLETTI, R. Vitrine e vidraça: crítica de mídia e qualidade no jornalismo. Covilhã: Labcom Books, 2010. p. 35-52.

REDE NACIONAL DE OBSERVATÓRIOS DE IMPRENSA (RENOI). Disponível em: <http://renoi.blogspot.com.br/>. Acesso em: 10 nov. 2015.

ROTHBERG, D. O conceito de enquadramento e sua contribuição à crítica de mídia. In: CHRISTOFOLETTI, R. Vitrine e vidraça: crítica de mídia e qualidade no jornalismo. Covilhã: Labcom Books, 2010. p. 53-68.

SILVA, G.; SOARES, R. L. Para pensar a crítica de mídias. Famecos, Porto Alegre, v. 20, n. 3, p. 820-839, set./dez. 2013.

SILVA, L. M.; PAULINO, F. O. Por que os observatórios não observam boas práticas. In: CHRISTOFOLETTI, R.; MOTTA, L. G. Observatórios de mídia: olhares da cidadania. São Paulo: Paulus, 2008. 